\title{
BEM-ESTAR E COMPORTAMENTO DE OVINOS EM SISTEMA INTENSIVO
}

\author{
Bruna Filipini ${ }^{1}$, Ariane Dantas $^{2^{*}}$, Aline Aparecida de Oliveira Montanha $^{3}$ \\ ${ }^{1}$ Departamento de Produção Animal da Faculdade de Medicina Veterinária e \\ Zootecnia, Universidade Estadual Júlio de Mesquita Filho (UNESP), Botucatu- SP, \\ Brasil. \\ $2^{*}$ Programa de Pós-Graduação em Biotecnologia Animal da Faculdade de Medicina \\ Veterinária e Zootecnia, Botucatu- SP, Brasil. dantas.vet@gmail.com \\ ${ }^{3}$ Doutora em Zootecnia pela Faculdade de Medicina Veterinária e Zootecnia (FMVZ), \\ Universidade Estadual Júlio de Mesquita Filho, Botucatu- SP, Brasil.

\section{Recebido em: 03/10/2016 - Aprovado em: 21/11/2016 - Publicado em: 05/12/2016 DOI: 10.18677/EnciBio 2016B 014}

\begin{abstract}
RESUMO
Para se entender o bem-estar animal, é necessário conhecimento de fisiologia, biologia e etologia. Assim, o desenvolvimento de um manejo animal que vise a qualidade de vida requer o respeito das cinco liberdades, para que o animal possa manter sua homeostase equilibrada e consiga enfrentar e vencer as situações impostas a ele, em um ambiente diferente do seu habitat natural. O confinamento de animais de produção consiste em um tipo de sistema de criação, onde os animais são mantidos em áreas delimitadas, recebendo água e alimentação de fácil acesso, até atingirem um determinado peso para, então, serem abatidos. Permite maior controle da alimentação fornecida e do status nutricional dos animais. Todavia, pode restringir a capacidade de movimentação, bem como o conforto e qualidade de vida dos animais, o que pode levar a alterações comportamentais. O comportamento natural de um animal é intrínseco a cada espécie e é singular para cada raça e indivíduo. Assim, deve-se ter o conhecimento do comportamento considerado normal do animal em seu habitat de origem, afim de melhor avaliar as condições de bem-estar. O bem-estar animal é tema cada vez mais discutido na área de produção animal e também pelos consumidores. A realização de mais estudos afim de permitir maior entendimento e esclarecimento sobre o tema, em suas mais diversas áreas, se faz interessante no presente cenário. Nesse sentido, esta revisão tem por objetivo descrever os conceitos e definições do bem-estar animal, com foco no sistema intensivo de criação de ovinos.
\end{abstract}

PALAVRAS-CHAVE: bem-estar animal, confinamento, cordeiros

\section{WELFARE AND SHEEP BEHAVIOR IN INTENSIVE SYSTEM}

ABSTRACT

To properly understand animal welfare, it is necessary physiology, biology and ethology knowledge. Thus, the development of animal husbandry, aimed to life quality, requires the respect of the five freedoms, so that the animal can maintain its homeostasis in balance and overcome situations imposed on him in a different environment from their natural habitat. Confinement of farm animals consists in a farming system where animals are kept in enclosed areas, getting food and water ENCICLOPÉDIA BIOSFERA, Centro Científico Conhecer - Goiânia, v.13 n.24; p.152 2016 
within easy reach, until the required weight is achieved. It allows intensive control on feeding and nutritional status of the animals but it can restrict the movement capability, as well as comfort and quality of life of animals, which can lead to behavioral changes. The natural behavior of an animal is particular to each species and is particular to each race and each individual. However, one must have knowledge of the expected behavior of the animal in its habitat of origin, in order to better assess welfare conditions and set standards. Animal welfare is increasingly being discussed in animal production area and also by consumers. Studies in order to provide a better understanding and clarification on this subject, and in $\mathrm{n}$ its various areas, are very valuable, regarding the present scenario. In this sense, this review aims to describe the concepts and animal welfare settings, focusing on sheep intensive system.

KEYWORDS: animal welfare, confinement, lambs

\section{INTRODUÇÃO}

Devido ao crescimento da população mundial, estima-se que até o ano de 2050 o setor agrícola terá que aumentar a produção em $60 \%$, para suprir a demanda por alimento no mundo (FOOD AND AGRICULTURE ORGANIZAÇÃO DAS NAÇÕES UNIDAS, FAO- 2012). Conjuntamente, a produção de alimentos de origem animal demonstra projeções substanciais de crescimento.

Para a produção mundial de carne, é esperado um aumento de $19 \%$ até o ano de 2021, principalmente das carnes de aves e bovinos. Para ovinos, estima-se que o crescimento da produção e consumo seja de aproximadamente $22 \%$, entre os anos de 2009 a 2021, principalmente nos países em desenvolvimento (FAO, 2012).

Essa expansão aguardada na produção de carne ovina será advinda, provavelmente, do aumento da produtividade, obtido através do uso de melhoramento genético, controle do estado sanitário e melhorias no manejo nutricional (THORNTON, 2010). Afim de suprir essa demanda, a produção de ovinos em sistema intensivo de criação também acompanhará esse aumento (FAO, 2012).

A terminação de cordeiros em confinamento proporciona maior taxa de crescimento, alto ganho de peso, padronização e qualidade das carcaças, entre outros benefícios (CARVALHO et al., 2007). Entretanto, é necessário maior discussão e reflexão sobre as possíveis interferências positivas e negativas que podem causar sobre o bem-estar dos animais (STAFFORD \& GREGORY, 2008).

O bem-estar animal é um estado de qualidade de vida que requer a implantação de práticas que visam a produção de alimento de origem animal com ética e de forma sustentável, sempre respeitando as necessidades e individualidades comportamentais de cada espécie (NOWAK et al., 2008).

Atualmente, a preocupação com o bem-estar animal é um dos principais interesses da produção animal moderna, estando de forma consistente no topo da maioria dos questionamentos levantados por consumidores e políticos da União Europeia, visto que a sociedade passou a conhecer melhor os sistemas de produção animal e a exigir a criação dos mesmos de maneira mais complacente (BOND et al., 2012). Em países em desenvolvimento, a valorização do bem-estar de animais de produção é uma inquietação crescente da sociedade (ASMARE, 2014).

E fundamental que os profissionais, empresários e estudantes da área estejam atualizados em relação aos conceitos de comportamento e bem-estar, principalmente o de animais mantidos em confinamento (ALVES et al. 2014). Nesse sentido, o presente trabalho tem por objetivo revisar os relatos científicos relativos a estes temas e analisar o efeito de alguns dos fatores extrínsecos e intrínsecos 
relacionados ao confinamento de ovinos, que podem afetar a produtividade e bemestar animal.

\section{DESENVOLVIMENTO}

\section{BEM-ESTAR ANIMAL (BEA)}

O conceito de BEA leva em consideração o estabelecimento de uma relação harmônica do organismo junto ao ambiente em que vive (BROOM, 2010). De acordo com DUNCAN (2005), a ampliação da definição de BEA consiste na importação de informações baseadas nas emoções, no funcionamento biológico do organismo e no comportamento natural dos animais em um determinado ambiente.

Para PARANHOS DA COSTA \& PINTO (2006) O BEA pode ser definido considerando três enfoques, sendo esses:

1- $\quad$ Estado psicológico (o BEA será determinado em função da observação dos sentimentos e emoções apresentados pelos animais, sendo que a observação de sentimentos como medo, ansiedade e frustação refletem redução do BEA).

2- $\quad$ Funcionamento fisiológico do animal (o BEA será considerado de acordo com a capacidade que o animal possui em manter suas funções orgânicas em equilíbrio, sem qualquer comprometimento do crescimento e reprodução, bem como alteração do comportamento normal da espécie).

3- $\quad$ Vida natural (o BEA é definido seguido a observação de um ambiente com características mais próximas possíveis do seu habitat natural, proporcionando condições de expressarem o comportamento característico da espécie).

De acordo com BROOM (2010), um animal exposto a condições de bem-estar apresentará adequado estado sanitário, adaptação ao meio em que vive e ausência de estresse. Para isso, é necessária a existência de um estado de variação tolerável das características fisiológicas de um indivíduo com o meio ambiente externo (BROOM \& JOHNSON, 1993).

A homeostase é a manutenção do equilíbrio das funções fisiológicas desempenhadas pelo organismo animal em consequência de interferências do meio externo. O controle desse processo é realizado por diferentes órgãos e gera um dispêndio significativo de recursos energéticos (DAVIDSON \& STABENFELDT, 2014). Segundo BROOM \& JOHNSON (1993), um desajuste homeostático, real ou potencial, gera no animal o desenvolvimento de necessidades. Essas, vão induzir o desenvolvimento de mecanismos ou estratégias no organismo. Todavia, se o indivíduo não conseguir suprir tais necessidades existentes, seu bem-estar poderá ser comprometido (BROOM, 2010).

De acordo com BOTREU et al. (2007) o BEA apresenta diversas facetas e varia entre as espécies e também entre os indivíduos, por isso é fundamental o conhecimento das características fisiológicas e comportamentais normais de cada espécie e das diferentes raças, para assim, melhor avaliar as condições de bemestar as quais os animais estão submetidos. WIDOWSKI (2009) afirma que para alcançar uma melhor compreensão do BEA é necessário, antes, o entendimento da relação entre as respostas emocionais e biológicos dos animais, bem como a avaliação do comportamento natural de cada espécie (Figura 1).

Segundo KILIÇ \& BOZKURT (2013) o padrão de bem-estar em criação de ovinos será maior, quanto mais elevada for a percepção do produtor quanto ao tema. O produtor deve adquirir uma visão mais ampla sobre os possíveis fatores que podem estar diretamente relacionados aos animais e ao ambiente em que vivem, 
uma vez que a melhoraria das condições de bem-estar resultam em benefícios, tanto para os animais como para a produção (HEMSWORTH \& COLEMAN, 1998).

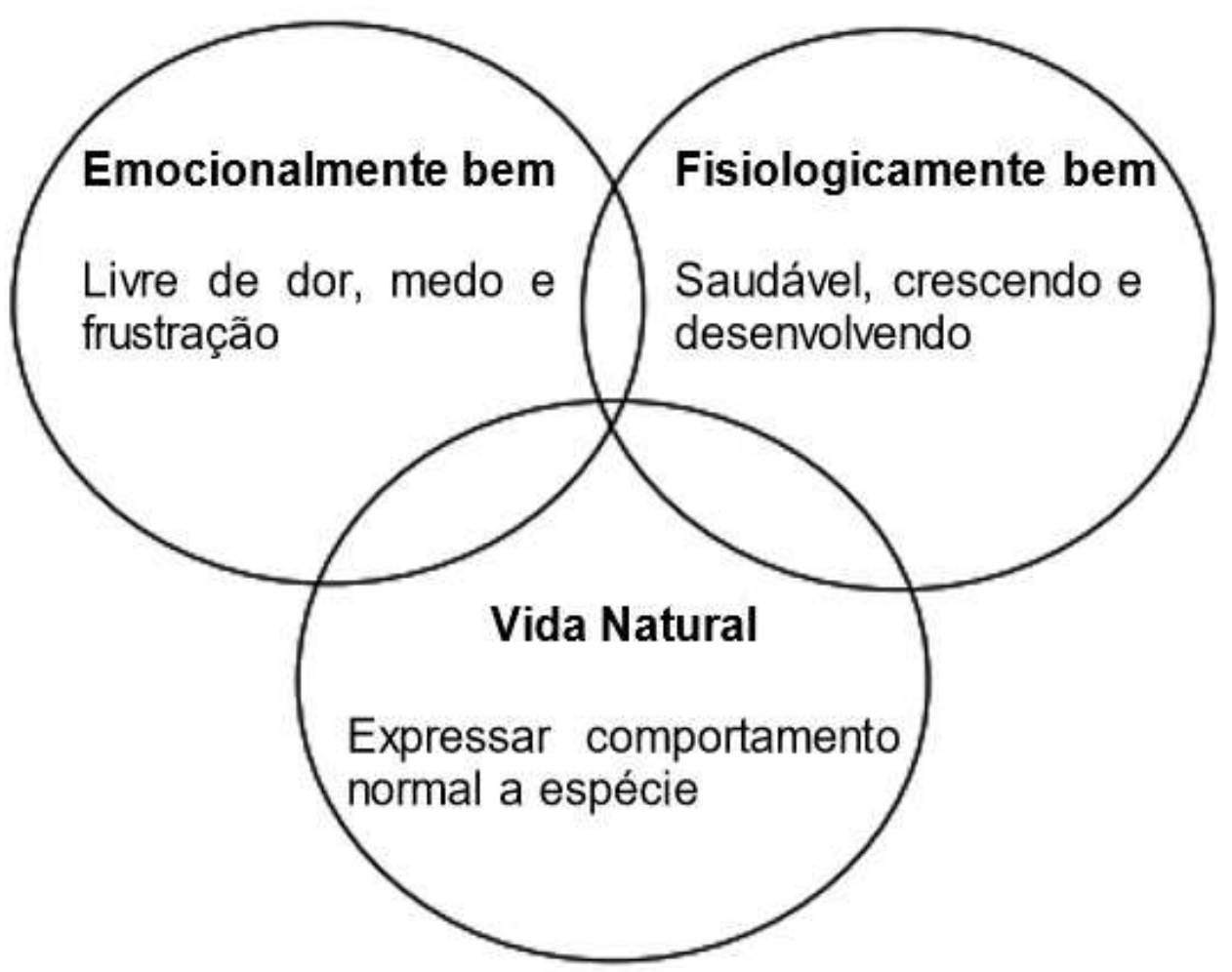

FIGURA 1. A definição de BEA está alicerçada em três pontos de vista que se sobrepõem (WIDOWSKI, 2009).

Os animais gregários, como por exemplo as ovelhas, são aqueles que apresentam como hábito viverem agrupadas (CAROPRESE, 2008). Em ovinos, uma característica muito importante é a sociabilidade, sendo comum o hábito de um animal sempre seguir um outro, durante o pastejo ou outras atividades, assim mantém-se sempre reunidos. $O$ isolamento em ovinos, gera uma situação de intenso estresse (DOYLE et al., 2010).

Devido ao modo de vida gregária, algumas características peculiares à espécie ovina foram bem desenvolvidas, tais como a capacidade visual. Ovinos possuem amplo campo de visão, entre 270 e $280^{\circ}$ (COULTER \& SCHMIDT, 1993) e apresentam boa capacidade de distinguir os rostos dos membros da sua própria raça (machos e fêmeas) e de diferentes espécies e raças (SUGNASEELAN et al., 2013). O que implica na adequação das práticas de manejo empreendidas segundo as características peculiares a espécie.

Os ovinos possuem sensibilidade auditiva bem desenvolvida, sendo essa característica muito importante, pois a vocalização só é usada em algumas situações sociais, tais como acasalamento, isolamento e separação da ovelha de seu cordeiro (KENDRICK et al., 2008). Sendo assim, a avaliação de vocalização em ovinos, apresenta-se como indicativo de situações de estresse (DOYLE et al., 2010).

Para que um sistema de criação (intensivo, extensivo ou semi-intensivo) de ovinos possa proporcionar condições adequadas de BEA, é necessário não só o conhecimento das características inerentes a espécie, como também o respeito das cinco liberdades, que consiste em um conjunto de "estados" ideais, criados em 1979, 
pelo Conselho de Bem-Estar de Animais de Produção (FARM ANIMAL WELFARE COUNCIL - FAWAC, 2002), cujos preceitos têm por finalidade manter os animais:

Animais livres de fome e sede: deve-se haver constante preocupação quanto ao manejo nutricional, sendo esse, elaborado afim de atender as exigências nutricionais de cada categoria animal, fornecido regularmente e em local de fácil acesso. A água fornecida aos animais, deve ser limpa, fresca, de boa qualidade e estar sempre disponível.

Dentro dessa diretriz está a preocupação com as instalações onde será fornecida a alimentação dos animais. Segundo recomendações da Empresa Brasileira de Pesquisa Agropecuária - EMBRAPA (2009), para ovinos confinados, o tamanho de cocho e de bebedouro para cordeiros deve ter dimensão entre 10 a 15 $\mathrm{cm}$ por cabeça e para animais adultos, medidas entre 25 a $30 \mathrm{~cm}$ por cabeça. Quanto ao bebedouro, esse deve ser um recipiente com boia, de fácil manutenção e limpeza, a qual deve ser feita duas vezes ao dia, e disposto em local sombreado.

Os cochos devem ser instalados afim de evitar o desperdício e a contaminação por fezes e urina, bem como facilitar o abastecimento. De acordo com SIMIONI et al. (2014) os cochos utilizados em confinamento de cordeiros devem apresentar as seguintes dimensões: $30-40 \mathrm{~cm}$ de altura do solo, $20 \mathrm{~cm}$ de profundidade e $30 \mathrm{~cm}$ de largura. Ressalta-se que o saleiro é outra instalação de muita importância e deve ser fixado sob a área coberta do curral.

Animais livres de desconforto: Consiste em assegurar que os animais sejam mantidos em ambiente com dimensionamento correto de parâmetros estruturais, além de limpo e seco. De acordo com a EMBRAPA (2009), as instalações para confinamento de ovinos devem ser construídas seguindo a orientação Leste-Oeste, para que os animais possam ser protegidos de calor, frio chuva, vento e umidade excessiva.

Seguindo as mesmas recomendações da EMBRAPA (2009), a quantidade de animais alocados por baias, deve respeitar as seguintes densidades: $1 \mathrm{~m}^{2}$ para cordeiro confinado em área com piso de concreto, entre 1,5 a $2 \mathrm{~m}^{2}$ para locais parcialmente cobertos e com chão batido e para instalações descobertas e de chão batido, a área deverá ser entre 2 a 2,5 $\mathrm{m}^{2}$, por causa do excesso de lama que pode se formar nas épocas de chuvas. O espaço para os animais confinados deve permitir não apenas a acomodação de todos os animais, mas, também, que se evite brigas.

Conforme LEME et al. (2013) em estudo realizado para verificar a influência da densidade de animais sobre o ganho de peso e comportamento de cordeiros confinados, observaram que a adequação da alta taxa de lotação proporciona mudança do padrão de ingestão de alimentos e melhoraria do ganho de peso, refletindo consequentemente na produtividade.

Segundo LIGNON \& BOTTECHIA (2005), as instalações para animais de produção podem ser simples e de baixo custo, porém devem ser eficientes, proporcionar conforto, espaço, proteção, qualidade sanitária e ambiência acústica e térmica, sempre respeitando o BEA e proporcionando qualidade de vida, em todo o processo de criação.

Animais livres de dor, lesões ou doenças: recomenda-se a realização de manejo sanitário adequado, visando à prevenção, diagnóstico e tratamento rápido de doenças. Aqueles animais que estiverem enfermos deverão ser direcionados para baias de enfermaria para serem devidamente tratados. A enfermaria por abrigar os animais doentes, deve localizar-se bem distante das demais instalações, para evitar o contato de doentes com os sadios. De preferência, deve localizar-se longe 
de fontes de barulhos frequentes e de movimentação de pessoas. A enfermaria deve oferecer o bem-estar e boas condições de higiene para os animais doentes (SIMIONI et al., 2014).

Animais livres para expressar seu comportamento característico: incide no respeito à capacidade do animal em manifestar o comportamento natural da espécie. Ressalta-se a importância do enriquecimento ambiental, principalmente para animais confinados, o que consiste na introdução de técnicas ou atividades que têm por finalidade gerar melhorias no ambiente (SEVI et al., 2009).

As atividades de enriquecimento ambiental devem ser pouco previsíveis e bastante motivadoras, apresentando-se como uma excelente ferramenta de redução do estresse em animais confinados, contribuindo para o desenvolvimento fisiológico e produtivo dos mesmos (MEYER et al., 2010).

Muitas são as possibilidades de objetos utilizados como enriquecimento ambiental para animais confinados e, tal variação pode fomentar preferências por parte dos animais retardando a perda de interesse pelos objetos, e para tanto, os testes de aversão ou preferência por um objeto de enriquecimento ambiental são de grande importância (VOLPATO, 2007).

Animais livres de medo e estresse: consiste na realização do manejo livre de ataque de predadores ou de qualquer situação que promova estresse, oferecendo aos animais um ambiente social estável assegurando condições que evitem sofrimento mental. Por isso, um tratador capacitado é muito importante, pois assim, o estado psicológico dos animais também será preservado.

Segundo GÓMEZ et al. (2010) os animais podem perceber diferentemente as práticas de manejo conforme suas experiências anteriores e suscetibilidade ao estresse. A organização da resposta ao agente estressor não é apenas função da percepção do referido agente, mas também de experiências passadas, o que permite o reconhecimento de uma dimensão psicológica do estresse.

Estas abordagens de preservação e manutenção do BEA propostas em 1979 não são destinadas a eliminar as fontes de estresse, mas sim, para prevenir o sofrimento do animal de situações ou ameaças potencialmente estressantes. Os princípios das cinco liberdades não representam um modelo perfeito, mas sim uma tentativa de obter melhores resultados de bem-estar na produção animal (COLEMAN et al., 2016).

Algumas das liberdades estabelecidas, como a de fome e sede, são universalmente reconhecidas e normalmente aplicadas, enquanto que as relativas ao comportamento e liberdade são aspectos que nem sempre são imediatamente entendidas (CARENZI \& VERGA, 2009).

Baseado no conceito das cinco liberdades, no Brasil, tem-se a Instrução Normativa no 56 (IN56) de 6 de novembro de 2008 (BRASIL, 2008), que estabelece as "Recomendações de Boas Práticas de Bem-Estar para Animais de Produção e de Interesse Econômico - REBEM", abrangendo os sistemas de produção e o transporte e aplicando-se tanto ao proprietário quanto a qualquer pessoa que cuide dos animais, sendo considerado como dever:

1- $\quad$ Proceder ao manejo cuidadoso e responsável nas várias etapas da vida do animal, desde o nascimento, e durante a criação e transporte;

2- Possuir conhecimentos básicos de comportamento animal a fim de proceder ao adequado manejo;

3- Proporcionar dieta satisfatória, apropriada e segura, adequada às diferentes fases da vida do animal; 
4- $\quad$ Assegurar que as instalações sejam projetadas apropriadamente aos sistemas de produção das diferentes espécies, de forma a garantir a proteção, a possibilidade de descanso e o bem-estar animal;

5- Manejar e transportar os animais de forma adequada para reduzir o estresse e evitar contusões e o sofrimento desnecessário;

6- Manter o ambiente de criação em condições higiênicas.

Embora existam contrastes entre os diferentes países quanto a legislação vigente sobre o BEA, essa é uma preocupação cada vez mais mundial e isso se deve provavelmente a força da globalização e do comércio internacional. Os cuidados com o BEA em todas as etapas de produção animal representam uma ótima perspectiva de agregar valor aos produtos de origem animal produzidos sob essa temática (VETTER et al., 2014).

Segundo CHRISTENSEN et al. (2012) através da manutenção e cuidados adequados com os animais, por intermédio de atitudes e práticas que visam preservar o BEA é possível aumentar a produtividade e o retorno econômico da atividade. Para que o progresso ocorra é necessário a sensibilização da sociedade, dando ênfase ao BEA, o que inclui o cumprimento das normas de proteção aos animais.

\section{BEM-ESTAR ANIMAL X CONFINAMENTO DE OVINOS}

Por muito tempo, os animais de produção eram vistos exclusivamente como recursos que poderiam resultar em lucros financeiros, sendo o bem-estar e a produtividade, conceitos antagônicos (MORRIS et al. 2012). No entanto, com a emergência da ciência do bem-estar, os interesses humanos e as necessidades dos animais foram conflitados, conduzindo a sociedade a uma reflexão sobre o consumo de alimentos providos ou não de preocupação com o BEA durante as diferentes etapas de produção (MONTOSSI et al., 2013; GRANDIN, 2014).

Segundo WATHES (2011), o aumento do estresse e do sofrimento dos animais tem efeito negativo na qualidade e produtividade dos alimentos. A relação existente entre o BEA e o desempenho produtivo deverá ser alicerçada, principalmente, no uso de práticas que melhorem a higiene do local, manejo dos animais e no fornecimento de uma nutrição adequada. De acordo com MONTOSSI et al. (2013), o BEA é considerado um dos maiores desafios à agropecuária mundial, devendo ser incorporado também como fator econômico do custo-benefício da produção.

A qualidade do manejo adotado no sistema de criação tem grande influência sobre o bem-estar e a produtividade. As práticas empreendidas diariamente no manejo dos animais refletem diretamente no comportamento animal que, por sua vez, afetam o bem-estar e o rendimento animal (HEMSWORTH et al., 2002).

Em ruminantes, é muito comum a prática do confinamento com finalidade de alcançar maior ganho de peso e, consequentemente, melhor retorno econômico (ZANETTE \& NEUMANN, 2012). Contudo, se os animais forem expostos à restrição alimentar, isolamento social, restrição espacial e locomotora e mantidos por longo período em um mesmo ambiente, sem quaisquer estímulos ou função adaptativa, podem desenvolver estereotipias, que são comportamentos diferentes ao que normalmente é atribuído à espécie (STAFFORD \& GREGORY, 2008).

Em um sistema intensivo, o ambiente de criação é significativamente diferente do ambiente natural dos animais. Isto pode prejudicar o BEA, podendo refletir no desempenho dos animais e consequentemente na lucratividade do produtor. A diminuição do BEA pode ser notada pela observação da ausência do comportamento habitual do animal, podendo esse apresentar estereotipias, tais 
como: balançar o corpo levando-o para frente, lados e para trás; enrolar a língua; ter comportamentos autodestrutivos como automutilação, lamber e comer o seu próprio pelo ou lã, ou até mesmo de seus companheiros; apetite descontrolado, agressividade, falhas reprodutivas e maternas (ausência de estro, impotência sexual nos machos, rejeição de filhotes) e reatividade anormal como pânico, apatia, inércia, hiperatividade (KEELING \& JENSEN, 2009).

Ressalta-se que comportamento anormal é um tipo de manifestação que o animal não apresentaria quando em vida livre, ou seja, é atípico da espécie, sendo que para ser considerada estereotipias, três características devem ser notadas, sendo estas: o tipo do comportamento realizado é fisicamente idêntico, o movimento realizado é repetitivo e a atividade desenvolvida não apresenta nenhum fundamento determinado. De acordo com LAUBER et al. (2012), a estereotipia é definida como uma compensação desenvolvida pelo animal, com a finalidade de dissipar as tensões e/ou frustrações, quando exposto a um ambiente com baixo bem-estar.

Segundo MOBERG (2000), as estereotipias podem causar nos animais desgastes da dentição, injúrias gastrointestinais, anemia, cólica e em casos mais graves pode resultar em morte, que em criação de cordeiros confinados pode ser de até $10 \%$.

De acordo com LAUBER et al. (2012), o comportamento estereotipado de babar/morder e mastigar o vácuo pode ser uma resposta condicionada por ingerir alimentos restritos. Deduz-se que ovinos confinados que comem lã possuem comportamento de forrageamento redirecionado, devido ao reduzido ato de forragear (VASSEUR et al., 2006).

YURTMAN et al. (2002) em estudo realizado com cordeiros confinados notaram aumento significativo de estereotipias orais, tais como o ato de babar e morder os comedouros durante a ingestão diária de alimentos. Já VASSEUR et al. (2006) observaram quadros onde os animais arrancavam a lã deles mesmos ou de outros animais quando submetidos a situações de confinamento.

COOPER \& JACKSON (1996), verificaram que ovinos confinados em instalação de piso ripado passam menos tempo deitados e ruminando e apresentam mais estereotipias orais depois de comer concentrado (como babar, morder, lamber ripas, comer lã e repetitiva lambedura) do que os animais mantidos em cama formada por palha. LAUBER et al. (2012), por meio de câmeras, analisaram os comportamentos apresentados por 96 ovinos da raça Merino, durante dois dias consecutivos (dia e noite), e constataram que o período em que as ovelhas são mais ativas é pela manhã, sendo que a maior parte do tempo, gastam em pé e em movimento $(81 \%)$.

Nesse mesmo experimento notou-se que principalmente no período da tarde, antes e após a alimentação, os atos de estimulação, mastigação e de cheirar apareciam demasiadamente, sendo considerados como comportamentos anormais. De acordo com MANSON (1991), o comportamento estereotipado muitas vezes atinge um ápice quando próximo da refeição, enquanto algumas estereotipias orais, tais como a mastigação, a manipulação do bebedor e comedouro tem um pico logo após a alimentação.

A observação de estereotipias orais em ovinos confinados estão associadas ao fornecimento de dietas com alto teor de proteína bruta. Os animais passam maior tempo mastigando e produzindo saliva, para assim tentar reduzir o efeito da acidez provocada no trato gástrico em virtude da dieta fornecida (YURTMAN et al., 2002). 


\section{AVALIAÇÃO DO BEM-ESTAR EM OVINOS}

O BEA, em diferentes situações e sistemas de produção, pode ser avaliado através da determinação do estado sanitário, comportamental, fisiológico e índices produtivos (BROOM, 2011). No quadro 1 estão apresentados os indicadores que podem servir como parâmetros de avaliação de BEA, segundo BROOM \& JOHNSON, (1993).

QUADRO 1. Indicadores de avaliação do BEA

Demonstração de uma variedade de comportamentos normais

Grau em que comportamentos fortemente preferidos podem ser apresentados

Indicadores fisiológicos de prazer

Indicadores comportamentais de prazer

Expectativa de vida reduzida

Crescimento ou reprodução reduzida

Danos corporais

Doença

Imunossupressão

Tentativas fisiológicas de adaptação

Tentativas comportamentais de adaptação

Doenças comportamentais

Auto-narcotização

Grau de aversão comportamental

Grau de supressão de comportamento normal

Grau de prevenção de processos fisiológicos normais e de desenvolvimento anatômico

As variações que podem ser observadas nas mensurações fisiológicas assim como do sistema imune, devem ser interpretadas com prudência, pois tais alterações podem ser atribuídas a diversos fatores e não necessariamente estão associadas ao estado pré-patológico condizente com a redução de bem-estar (MOBERG, 2000).

A dosagem de cortisol é a avaliação mais comumente utilizada para determinação do BEA, sendo que altas concentrações desse hormônio, sugerem aumento do nível de estresse. Apesar da fácil mensuração, a quantidade de hormônio sintetizado e secretado no organismo oscila ao longo do dia e em virtude do próprio manejo da coleta de sangue, fatores que podem alterar os níveis desse hormônio durante a observação (BROOM, 2010).

Outros hormônios tais como a prolactina, ocitocina, hormônio do crescimento, hormônio estimulante da tireoide, hormônio luteinizante e folículo estimulante podem ser afetados pelo estresse (MOLENTO, 2005). Sabe-se que as alterações na liberação dessas substâncias são mecanismos de defesa diante as situações que julgam estressantes, podendo ser acompanhadas por variações comportamentais, neuroendócrinas, imunológicas, cardiovasculares e gastrintestinais (MOLENTO, 2005).

Para avaliação do estado harmônico do animal para com o ambiente, pode-se analisar também a dificuldade que ele demonstra ao tentar se adaptar ao meio em que vive (BROOM, 2011). Quanto mais dificuldades o animal tiver, mais recursos precisará despender para se adequar a situação em que se encontra. Esses 
recursos são, na maioria, fatores comportamentais e fisiológicos, e, por meios dessas alterações, pode-se determinar o BEA (KILIÇ \& BOZKURT, 2013).

No processo de adaptação ao ambiente, 0 animal pode enfrentar hipoteticamente três cenários distintos. No primeiro, se não tiver possibilidades de adaptação ao ambiente, ele, ou irá a óbito, ou sofrerá de doenças e lesões causadas pelo meio em que vive, indicando a falta de bem-estar. Segunda situação, poderá ocorrer a adaptação, porém com alto custo biológico para o indivíduo, causando o estresse. No terceiro cenário, o animal tem uma adaptação possível e fácil ao ambiente e o bem-estar está em um nível satisfatório (KILIÇ \& BOZKURT, 2013).

Outros mecanismos para estudo do BEA envolvem a avaliação da expressão gênica, uma vez que a resposta celular do organismo diante uma situação estressante pode induzir alterações de genes específicos, culminado na síntese de proteínas específicas, cuja funções são de proteger as células e reequilibrar a homeostase, sendo considerado como um mecanismo universal de defesa contra as injúrias e agressões sofridas pelos animais. Segundo MOLENTO (2005), estudos realizados na área de expressão dessas proteínas de estresse, podem proporcionar a otimização do sistema de produção animal.

A análise concomitante do comportamento de um animal frente a certas situações estressantes e diante da realização de determinadas tarefas de manejo, podem servir como parâmetro de seleção de animais com características desejáveis ao melhoramento de um rebanho (HÖTZEL \& MACHADO FILHO, 2004).

Segundo OCAMPO (2011) a avaliação do estado de BEA deve ser feita seguindo um conjunto de análises integradas e não tomando por base simplesmente uma única metodologia de avaliação, pois dessa forma, avaliação do BEA pode mostrar-se pouco precisa e muito tendenciosa. É importante destacar a necessidade de pesquisas realizadas simultaneamente nas diferentes etapas do processo de produção animal, afim de determinar quais fatores intrínsecos e extrínsecos podem estar envolvidos nesse segmento.

\section{CONSIDERAÇÕES FINAIS}

O sistema de produção intensivo, com a inclusão de concentrados nas dietas, permite maior taxa de crescimento, ganho de peso e menor tempo necessário para os animais atingirem o peso para o abate. No entanto, apesar desses benefícios, requer-se maior discussão sobre as possíveis interferências dessa prática sobre o bem-estar dos animais.

A preocupação com o bem-estar animal é uma questão cada vez mais presente entre os consumidores e produtores e tem apresentado crescente influência na tomada de decisões durante a compra dos alimentos por parte do consumidor. Logo, a realização de pesquisas nessa área se faz fundamental, pois permitirá maior compreensão da temática, bem como o desenvolvimento de técnicas que otimizem, simultaneamente, o rendimento econômico e a qualidade de vida de animais em confinamento.

\section{REFERÊNCIAS}

ALVES, L. G. C.; OSÓRIO, J. C. S.; FERNANDES, A. R. M.; RICARDO, H. A.; CUNHA, C. M. Produção de carne ovina com foco no consumidor. Enciclopédia Biosfera, Centro Científico Conhecer, v. 10, n. 18, p. 2399-2415, 2014. 
ASMARE, B. Farm Animal Welfare and Handling in the Tropics: The Ethiopia Case. Hindawi Publishing Corporation Advances in Agriculture, v. 1, n. 8, p. 1-7, 2014. Disponível em: <http://dx.doi.org/10.1155/2014/428129>. doi: 10.1155/2014/428129.

BOND, G. B.; ALMEIDA, R.; OSTRENSKY, A.; MOLENTO, C. F. M. Métodos de diagnóstico e pontos críticos de bem estar de bovinos leiteiros. Ciência Rural, v. 42, n. 7, p. 1286-1293, 2012. Disponível em: <http://dx.doi.org/10.1590/S010384782012005000044>. doi: 10.1590/S0103-84782012005000044.

BRASIL. Instrução Normativa N. 56, de 06 de novembro de 2008. Recomendações De Boas Práticas De Bem-Estar Para Animais De Produção E De Interesse Econômico. Diário Oficial, Brasília, 07 de novembro de 2008. Seção 1, p. 5.

BROOM, D. M.; JOHNSON, K. G. Stress and animal welfare. Dordrecht: Kluver Academic Publishers, 1993.138 p.

BROOM, D. M. Animal welfare: An aspect of care, sustainability, and food quality required by the public. Animal welfare in education and research. Journal of Veterinary Medical Education, v. 37, n. 1, p. 83-88, 2010. Disponível em: <http://dx.doi.org/10.3138/jvme.37.1.83>. doi: 10.3138/jvme.37.1.83.

BROOM, D. M. Animal welfare: concepts, study methods and indicators. Revista Colombiana de Ciencias Pecuarias, v. 24, n. 3, p. 306-321, 2011.

BOTREAU, R.; VEISSIER, I.; BUTTERWORTH, A.; BRACKE, M. B. M.; KEELING, L. J. Definition of criteria for overall assessment of animal welfare. Animal Welfare, v. 16, n. 2, p. 225-228, 2007. Disponível em: <10.1017/S1751731107000535>. doi: $10.1017 / \mathrm{S} 1751731107000535$.

CARENZI, C.; VERGA, M. Animal welfare: review of the scientific concept and definition. Italian Journal of Animal Science, v. 8, n. 1, p. 21-30, 2009. Disponível em: <http://dx.doi.org/10.4081/ijas.2009.s1.21>. doi: 10.4081/ijas.2009.s1.21.

CAROPRESE, M. Sheep housing and welfare. Small Ruminant Research, v. 76, n. 2, p. 21-25, 2008. Disponível em:

<http://dx.doi.org/10.1016/j.smallrumres.2007.12.015>. doi:

10.1016/j.smallrumres.2007.12.015.

CARVALHO, S.; BROCHIER, M. A.; PIVATO, J.; TEIXEIRA, R. C.; KIELINGI, R. Ganho de peso, características da carcaça e componentes não-carcaça de cordeiros da raça Texel terminados em diferentes sistemas alimentares. Ciência Rural, v. 37, n. 3, p. 821-827, 2007. Disponível em: <http://dx.doi.org/10.1590/S010384782007000300034>. doi: 10.1590/S0103-84782007000300034.

COLEMAN, G.; JONGMAN, E.; GREENFIELD, L.; HEMSWORTH, P. Farmer and public attitudes toward lamb finishing systems. Journal of Applied Animal Welfare Science, v. 19, n. 2, p. 198-209, 2016. Disponível em: $<10.1080 / 10888705.2015 .1127766>$. doi: 10.1080/10888705.2015.1127766. 
COULTER, D. B.; SCHMIDT, G. M. Special senses. In: SWENSON, M. J.; REECE, W. O. Duke's physiology of domestic animals. 11. ed. Ithaca: Comstock Publishing Associates, 1993. $1024 \mathrm{p}$.

COOPER, J.; JACKSON, R. A. comparison of the feeding behaviour of sheep in straw yards and on slats. Applied Animal Behaviour Science, v. 49, n. 1, p. 99, 1996. Disponível em: <http://dx.doi.org/10.1016/0168-1591(96)87691-X>. doi: 10.1016/0168-1591(96)87691-X.

CHRISTENSEN, T.; LAWRENCE, A.; LUND, M.; STOTT, A.; SANDOE, P. How can economists help to improve animal welfare? Animal Welfare. Animal Welfare, v. 21, n. $1, \quad$ p. $1-10,2012 . \quad$ Disponível em: <http://dx.doi.org/10.7120/096272812X13345905673449>. doi: $10.7120 / 096272812 \times 13345905673449$.

DAVIDSON, P. A.; STABENFELDT, H. G. Cunningham Tratado de Fisiologia Veterinária. 5. ed. Rio de Janeiro: Elsevier, 2014. 624 p.

DOYLE, R. E.; FISHER, A. D.; HINCH, G. N.; BOISSY, A. Caroline Lee Release from restraint generates a positive judgement bias in sheep. Applied Animal Behaviour Science, v. 122, n. 1, p. 28-34, 2010. Disponível em: <http://dx.doi.org/10.1016/j.applanim.2009.11.003>. doi: 10.1016/j.applanim.2009.11.003.

DUNCAN, I. J. H. Science-based assessment of animal welfare: farm animals. Revue Scientifique et Technique International Office of Epizootics, v. 24, n. 2, p. 483-492, 2005.

EMBRAPA. Estresse pode diminuir produtividade animal. 2009. Disponível em: $<$ https://www.infoteca.cnptia.embrapa.br/bitstream/doc/748310/1/doc93.pdf>. Acesso em: 29 setembro 2016.

FARM ANIMAL WELFARE ADVISORY COUNCIL - FAWAC. Animal Welfare Guidelines for Sheep Farmers. 2002. Disponível em: $<$ http://www.agriculture.gov.ie/fawac/publications/Sheep_Guidelines.pdf>. Acesso em: 03 setembro 2016.

FOOD AND AGRICULTURE ORGANIZATION OF THE UNITED NATIONS - FAO, 2012. OECD-FAO agricultural outlook 2012-2021. Disponível em: <http://www.agrioutlook.org/>. Acesso em: 29 setembro 2016.

GRANDIN, T. Animal welfare and society concerns finding the missing. Meat Science, v. 98, n. 3, p. 461-469, 2014. Disponível em: <http://dx.doi.org/10.1016/j.meatsci.2014.05.011>. 10.1016/j.meatsci.2014.05.011.

GÓMEZ, J. M. D.; FISCHER, V.; POLI, C. H. E. C.; CARVALHO, P. C. F.; PEGORARO, E. J.; MACARI, S. Efeitos da oferta de forragem, do método de pastejo, dos dias de avaliação e da raça no comportamento e temperamento de ovinos. Revista Brasileira de Zootecnia, v. 39, n. 8, p. 1840-1848, 2010. Disponível 
em: <http://dx.doi.org/10.1590/S1516-35982010000800029>. doi: 10.1590/S151635982010000800029 .

HEMSWORTH, P. H.; COLEMAN, G. J. Human-livestock interactions: The stockperson and the productivity and welfare of intensively-farmed animals. Journal of the South African Veterinary Association, v. 69, n. 3, p. 89-92, 1998. Disponível em: <10,4102/jsava.v69i3.832>. doi: 10,4102/jsava.v69i3.832.

HEMSWORTH, P. H.; COLEMAN, G. J.; BARNETT, J. L.; BORG, S.; DOWLING, S. The effects of cognitive behavioral intervention on the attitude and behavior of stockpersons and the behavior and productivity of commercial dairy cows. Journal of Animal Science, v. $80, \quad$ n. 1, p. 68-78, 2002. Disponível em: $<10.2527 / 2002.80168 x>$. doi: $10.2527 / 2002.80168 x$.

HÖTZEL, M. J.; MACHADO FILHO, L. C. P. Bem-estar animal na agricultura do século XXI. Revista de Etologia, v. 6, n. 1, p. 3-15, 2004.

KEELING, L.; JENSEN, P. The ethology of domestic animals, 2. ed. Wallingford: CABI Publishing, 2009. 264 p.

KENDRICK, K. M. Facial and vocal discrimination in sheep. In: DWYER, C. M. The Welfare of Sheep. 6. ed. Edinburgh: Springer Netherlands, 2008. p. 135-157.

KILIÇ, I.; BOZKURT, Z. The Relationship between farmers' perceptions and animal welfare standards in sheep farms. Asian-Australasian Journal of Animal Sciences, v. 26, n. 9, p. 1329-1338, 2013. Disponível em: <http://dx.doi.org/10.5713/ajas.2013.13124>. doi: 10.5713/ajas.2013.13124.

LAUBER, M.; NASH, J. A.; GATT, A.; HEMSWORTH, P. H. Prevalence and incidence of abnormal behaviours in individually housed sheep. Animals, v. 2, n. 1, p. 27-37, 2012. Disponível em: <10.3390/ani2010027>. doi: 10.3390/ani2010027.

LEME, T. M. C. TITTO, E. A. L.; TITTO, C. G.; PEREIRA, A. M. F.; CHIQUITELLI, N. $M$. Influence of stocking density on weight gain and behavior of feedlot lambs. Small Ruminant Research, v. 115, p. 1-6, 2013. Diposnível em: <http://dx.doi.org/10.1016/j.smallrumres.2013.07.010>. doi: 10.1016/j.smallrumres.2013.07.010.

LIGNON, G. B.; BOTTECHIA, R. J. Criação de animais sob influência de um sistema integrado de produção agroecológica. In: AQUINO, A. M.; ASSIS, R. L. Agroecologia: princípios e técnicas para uma agricultura orgânica sustentável. Seropédica: Embrapa Agrobiologia, 2005. p. 342-386.

MANSON, G. J. Stereotypies: A critical review. Animal Behaviour, v. 41, n. 6, p. 6374, 1991. Disponível em: <http://dx.doi.org/10.1016/S0003-3472(05)80640-2>. doi: 10.1016/S0003-3472(05)80640-2.

MEYER, F. S.; PUPPE, B.; LANGBEIN, J. Cognitive enrichment in zoo and farm animals - implications for animal behaviour and welfare. Berl Munch Tierarztl 
Wochenschr, v. 123, n. 11-12, p. 446-56, 2010. Disponível em: <10.2374/00059344-123-4>. doi: 10.2374/0005-9344-123-4.

MOBERG, G. P. Biological response to stress: implications for animal welfare. In: MOBERG, G. P.; MENCH, J. A. The biology of animal stress: basic principles and implications for animal welfare. Wallingford: CABI Publishing, 2000. p. 1-22.

MOLENTO, C. Bem-estar e produção animal: Aspectos Econômicos - revisão. Archives of Veterinary Science, v. 10, n. 1, p.1-11, 2005. Disponível em: <http://dx.doi.org/10.5380/avs.v10i1.4078>. doi: 10.5380/avs.v10i1.4078.

MONTOSSI, F.; FONT-I-FURNOLS, M.; DEL CAMPO, M.; SAN JULIÁN, R.; BRITO, G.; SAÑUDO, C. Sustainable sheep production and consumer preference trends: Compatibilities, contradictions, and unresolved dilemas. Meat Science, v. 95, n. 4, p. 772-789, 2013. Disponível em: <http://dx.doi.org/10.1016/j.meatsci.2013.04.048>. doi: 10.1016/j.meatsci.2013.04.048.

MORRIS, J. E.; CRONIN, G. M.; BUSH, R. D. Improving sheep production and welfare in extensive systems trough precision sheep management. Animal Production Science, v. 52, n. 7, p. 665-670, 2012. Disponível em: <http://dx.doi.org/10.1071/AN11097>. doi: 10.1071/AN11097.

NOWAK, R.; PORTER, R. H.; BLACHE, D.; DWYER, C. M. Behaviour and the welfare of the Sheep. In: DWYER, C. M. The Welfare of sheep. 6. ed. Edinburgh: Springer Netherlands, 2008. 366 p.

OCAMPO, A.; CARDOZO, A.; TARAZONA, A.; CEBALLOS, M.; MURGUEITIO, E. La investigación participativa en bienestar y comportamiento animal en el trópico de América: oportunidades para nuevo conocimiento aplicada. Revista Colombiana Ciencias Pecuarias, v. 24, p. 332-346, 2011.

PARANHOS DA COSTA, M. J. R.; PINTO, A. A. Bem-estar animal. In: RIVERA, A. B.; AMARAL, M. H.; NASCIMENTO, V. P. Ética e bioética aplicadas a medicina veterinária. Goiânia: Editora Universidade Federal de Goiás, 2006. p. 105-130.

STAFFORD, K.; GREGORY, N. Implications of intensification of pastoral animal production on animal welfare. New Zealand Veterinary Journal, v. 56, n. 6, p. 27480, 2008. Disponível em: <10.1080/00480169.2008.36847>. doi: 10.1080/00480169.2008.36847.

SEVI, A.; CASAMASSIMA, D.; PULINA, G.; PAZZONA, A. Factors of welfare reduction in dairy sheep and goats. Review article. Italian Journal of Animal Science, $\quad$ v. 8 , p. 81-101, 2009. Disponível em: <http://dx.doi.org/10.4081/ijas.2009.s1.81>. doi: 10.4081/ijas.2009.s1.81.

SIMIONI, T. A.; GOMES, F. J.; MOUSQUER, C. J.; TEIXEIRA, U. H. G.; CASTRO, W. J. R.; PAULA, D. C.; HOFFMANN, A.; FERNANDES, G. A. Modificações ambientais em instalações para ovinos em sistemas de pastejo e confinamento. PUBVET- Publicações em Medicina Veterinária e Zootecnia, v. 8, n. 6, 2014. 
SUGNASEELAN, S.; PRESCOTT, N. B.; BROOM, D. M., WATHES, C. M.; PHILLIPS, C. J. C. Visual discrimination learning and spatial acuity in sheep. Applied Animal Behaviour Science, v. 147, n. 1, p. 104-111, 2013. Disponível em: $<10.1016 /$ j.applanim.2013.04.012>. doi: 10.1016/j.applanim.2013.04.012.

THORNTON, P. K. Livestock production: Recent trends, future prospects. Philosophical Transactions Royal Society Biology Science, v. 365, n. 10, p. 2853-2867, 2010. Disponível em: <10,1098/rstb.2010.0134>. doi: $10,1098 /$ rstb.2010.0134.

VASSEUR, S.; PAULL, D. R.; ATKINSON, S. J.; COLDITZ, I. G.; FISHER, A. D. Effects of dietary fibre and feeding frequency on wool biting and aggressive behaviours in housed Merino Sheep. Australian Journal of Experimental Agriculture, v. 46, n. 7, p. 777-782, 2006. Disponível em: <http://dx.doi.org/10.1071/EA05320>. doi: 10.1071/EA05320.

VETTER, S.; VASA, L.; ÓZSVÁRI, L. Economic aspects of animal welfare. Acta Polytechnica Hungarica, v. 11, n. 7, p. 119-134, 2014.

VOLPATO, G. L. Considerações metodológicas sobre os testes de preferência na avaliação do bem-estar em peixes. Revista Brasileira de Zootecnia, v. 36, p.53-61, 2007. Disponível em: <http://dx.doi.org/10.1590/S1516-35982007001000006>. doi: 10.1590/S1516-35982007001000006.

WATHES, C. Economics and farm animal welfare. 2011. Disponível em: <https://www.gov.uk/government/uploads/system/uploads/attachment_data/file/3249 64/FAWC_report_on_economics_and_farm_animal_welfare.pdf >. Acesso em: 09 setembro 2016.

WIDOWSKI T. M. The Science behind the issues in animal welfare. Disponível em: $<$ http://www.thepigsite.com/articles/14/pig-welfare/2862>. Acesso em: 04 setembro 2016.

YURTMAN, I. Y.; SAVAS, T.; KARAAGAC, F.; COSKUNTUNA, L. Effects of daily protein intake on the oral stereotypic behaviours in energy restricted lambs. Applied Animal Behaviour, v. 77, n. 1, p. 77-88, 2002. Disponível em: <http://dx.doi.org/10.1016/S0168-1591(02)00025-4>. doi: 10.1016/S01681591(02)00025-4.

ZANETTE, P. M.; NEUMANN, M. Confinamento como ferramenta para incremento na produção e na qualidade da carne de ovinos. Ambiência Guarapuava, v. 8, n. 2, p. 415-426, 2012. 